\title{
Lady Oracle: la mascarada gótica
}

\section{Marina FE PASTOR \\ Universidad Nacional Autónoma de México}

\begin{abstract}
En este ensayo se propone que la ironía y la parodia, características de la escritura de Margaret Atwood, son estrategias narrativas que hacen posible la desconstrucción de las novelas góticas populares (costume gothics) en su propia novela gótica Lady Oracle. Se muestra cómo el uso y el abuso de las convenciones del género pone en evidencia la feminidad como una mascarada y el género como un performance.
\end{abstract}

PALABRAS CLAVE: gótico, parodia, mascarada, performance, 1976.

This essay argues that irony and parody, characteristics of Margaret Atwood's writing, are narrative strategies that make it possible to deconstruct the popular costume gothics in her own gothic novel Lady Oracle. It shows how the use and abuse of gothic conventions turn femininity into a masquerade and how gender becomes a performance.

KEY WORDS: gothic, parody, masquerade, performance, 1976.

I planned my death carefully; unlike my life, which meandered along from one thing to another, despite my feeble attempts to control it. My life had a tendency to spread, to get flabby, to scroll and festoon like the frame of a baroque mirror, which came from following the line of least resistance. ${ }^{1}$

Margaret Atwood

A diferencia de muchas otras novelas, Lady Oracle de Margaret Atwood empieza haciendo referencia a la propia muerte, la muerte de esta mujer que narra su vida y su muerte ficticias en primera persona, una primera persona inestable no sólo como voz narradora sino como personaje. Son ficticias porque así como su muerte es fingida, una mera representación o performance para engañar a todos, el relato de su vida, objeto de

\footnotetext{
${ }^{1}$ Planeé mi muerte cuidadosamente; a diferencia de mi vida, que serpenteaba de una cosa a otra, a pesar de mis débiles intentos por controlarla. Mi vida tendía a extenderse, a aflojarse, a dibujar volutas y guirnaldas como las del marco de un espejo barroco, lo que sucedía por seguir la línea de menor resistencia (Atwood, 1976: 3). (Todas las traducciones son mías. M. F.)
} 
la narración, se parece más a una novela gótica que a una autobiografía. Por otra parte, si bien es cierto que el narrador homodiegético es siempre poco confiable (tan poco confiable, podríamos pensar, como cualquier persona que cuenta o escribe su vida), Joan, la protagonista y narradora, lo es menos no sólo porque su vida es tan enredada como "el marco de un espejo barroco", sino porque, como escritora de novelas góticas, confunde su vida con la ficción (o más bien "escribe" su vida como si se tratara de una de sus propias novelas).

Como señala Luz Aurora Pimentel en El relato en perspectiva: "toda narración homodiegética ficcionaliza el acto mismo de la narración. El narrador deja de ser una entidad separada y separable del mundo narrado para convertirse en un narrador-personaje" (1998: 140). Sin embargo, en mi opinión, esto sucede en grados diferentes y con distintos propósitos, dependiendo de la novela o el relato. En este caso, la propia narradora siempre parece confundir la realidad con la ficción, su vida con las novelas, y si bien Joan "escribe" su vida al narrarla en la novela que leemos, nunca es claro si ese yo que narra lo hace por escrito o no, y no sabemos si se lo cuenta a alguien ni por qué lo haría si en realidad planeó su muerte para desaparecer. De esta manera, ya desde el primer párrafo de la novela dudamos de toda posible verosimilitud en esta historia de vida y muerte. Por otra parte, al tratarse de una mujer que aparentemente nunca ha podido definir su propia identidad, que se ha pasado la vida ocultando su "verdadero yo" (el cual, por esa misma razón, en realidad nunca ha existido) y que además se dedica de manera profesional a inventar historias, muy pronto sospechamos de ella como narradora.

Atwood publica esta novela neogótica en 1976, en una década en que el feminismo y la crítica literaria feminista estaban en pleno apogeo, y mediante su escritura irónica y paródica va a hacer una crítica feminista y posmoderna de un género bien conocido y explotado: el gótico. Joan Foster, la narradora y protagonista de la novela que escribe Atwood, es a su vez una escritora de novelas góticas populares (custom gothics) que está en el proceso de escribir una novela sobre Charlotte, una joven que ha sido empleada en una mansión para arreglar las joyas de la señora de la casa, Felicia. Esta última, a su vez, engaña a su marido mientras que él (quien es al mismo tiempo el héroe y el villano) trata de seducir a la muchacha inocente, perfecta víctima gótica. En la mansión, o castillo, como suele suceder en el gótico tradicional, hay un laberinto, y desde que Charlotte llega el cochero le advierte que no entre en éste pues si lo hace nunca logrará salir de ahí. Joan escribe esta novela en Italia, a donde ha huido escapando de Canadá y de todos sus familiares y amigos después de haber fingido su propia muerte, en un intento por salir del laberinto en que se ha convertido su propia vida. La novela empieza entonces al final, o casi, de una serie de acontecimientos de la vida de la escritora, desde su infancia y su relación con la madre y la tía, hasta los últimos sucesos que la llevan a representar su muerte como la única manera posible de huir de tantos problemas y complicaciones en que se ve envuelta.

La figura del laberinto, uno de los motivos góticos por excelencia, como lo es también el de la huida, el viaje o la búsqueda (quest), en la novela de Atwood se convertirá en una metáfora central ya que el texto mismo, el relato supuestamente autobiográfico de 
Joan, irá adquiriendo las características laberínticas del espejo barroco mencionado al principio. Las protagonistas góticas, sobre todo en su versión popular (costume gothics) que se puso tan de moda en los países anglosajones en las décadas de los sesentas y setentas, siempre están huyendo de algo, o sobre todo de alguien, y en su huida pueden fácilmente perderse. Y así como su heroína trata de escapar, Joan, la escritora, también huye sin lograr realmente encontrar la salida del laberinto cada vez más enredado de su vida. Sucede entonces que la voz narradora llega a confundirse con la de uno de sus propios personajes femeninos, o más bien, se convierte en un personaje creado por ella misma, y esto hace que Joan, como narradora de su propia historia, sea cada vez menos confiable, ya que parece confundir su vida personal (o hacer que el lector, su cómplice, la confunda) con las vidas inventadas de sus propios personajes de ficción. La única diferencia es, tal vez, que en sus novelas siempre recurre a una narradora omnisciente, mientras que en su autobiografía (la novela que nosotros leemos) sólo conoce la perspectiva del yo narrado y no puede nunca dar cuenta de lo que está en la mente los demás, razón por la cual siempre tiene dudas en cuanto a lo que sienten y a lo que piensan de ella los otros. Y es que Joan, como suele sucederle a las mujeres, siempre se ha sentido puesta en tela de juicio por la gente que la rodea (excepto por su tía), y nunca ha estado a la altura de sus exigencias, sobre todo en lo que se refiere a su cuerpo y su gordura que la han hecho sentirse francamente monstruosa.

Ellen Moers, la primera crítica feminista que hiciera referencia a la importancia en el gótico femenino de la relación conflictiva con el propio cuerpo y la propia sexualidad, pone el énfasis en cómo las mujeres se ven a sí mismas a partir de la mirada de los otros y cómo el gótico explora justamente este aspecto de la escritura femenina: "Despair is hardly the exclusive province of any one sex or class in our age, but to give visual form to the fear of self, to hold anxiety up to the Gothic mirror of the imagination, may well be more common in the writings of women than of men. While I cannot prove this statistically, I can offer a reason: that nothing separates female experience from male experience more sharply, and more early in life, than the compulsion to visualize the self" $(1985: 107){ }^{2}$

El hecho de sentirse o saberse sometida a la mirada (o la vigilancia) de los otros hace que en el gótico femenino aparezca el sujeto escindido, la mujer dividida en diferentes facetas, "the numerous split heroines and doubles in the classic feminine gothic" (Becker, 1999: 158) que, como la protagonista de esta novela, es al mismo tiempo una y muchas, diferentes "personajes" que son como el reflejo deformado uno del otro, sin que quede claro cuál es, si es que existe, el "original": "Joan's creation, recognition and treatment of these 'selves' and the relating multiplying proceses becomes one of

2 "La desesperación es difícilmente propiedad exclusiva de ningún sexo o clase en nuestra época, pero darle forma visual al miedo a uno mismo, colocar la ansiedad ante el espejo gótico de la imaginación, puede ser más común en los escritos de las mujeres que en los de los hombres. Aunque no puedo demostrar esto estadísticamente, puedo dar una razón: que nada separa la experiencia femenina de la masculina más agudamente y más temprano en la vida, que la compulsión de verse a uno mismo".

3 "Las numerosas heroínas divididas y los dobles en el gótico femenino clásico". 
the trajectories of her story; and much of her activity is concerned with ordering these selves by means of separation..."4 (idem). La heroína gótica posmoderna es, en este caso, un sujeto fragmentado, un personaje que se ve obligado a dividirse o separarse en diferentes personalidades sin saber realmente, ni siquiera preguntárselo, quién es la verdadera Joan. Al mismo tiempo, y ésta es una de las características del gótico femenino clásico, el hecho de sentirse vistas y juzgadas por los demás y de no saber quiénes son, hace que las heroínas del gótico femenino se perciban a sí mismas como monstruos (freaks). Siguiendo así las convenciones del gótico femenino, Joan tiene su etapa monstruosa: de niña y adolescente es obesa y come cada vez más para torturar a su madre: "The war between myself and my mother was on in earnest; the disputed territory was my body [...] I swelled visibly, relentlessly, before her very eyes, I rose like dough, my body advanced inch by inch towards her across the dinning-room table, in this at least I was undefeated"5 (73).

La gordura de Joan que la convierte en una freak es una característica de los personajes del gótico femenino, mujeres que se viven a sí mismas como monstruos al tener algún rasgo (físico o de carácter) "en exceso". Asimismo, otra característica del gótico femenino es la relación conflictiva con la madre, autoritaria y represiva. En este caso, la venganza de Joan frente a ella es justamente este crecimiento desmesurado y grotesco de su cuerpo que la hace sentirse poderosa y que es, además, la única manera como puede desafiarla. Frente a este tipo de convenciones, en su reescritura posmoderna Atwood recurre a la exageración y al exceso para explorar las posibilidades del género y al mismo tiempo hacer evidente sus mecanismos técnicos e ideológicos.

Una de las estrategias narrativas posmodernas a la que recurre Atwood en esta novela es la parodia, la cual funciona a partir del uso y abuso de dichas convenciones. La parodia sirve para desnaturalizar las estructuras góticas tradicionales, entre ellas la autoridad del autor omnisciente y el final donde todo queda resuelto de manera definitiva. Su pluma irónica y feminista inventa el personaje de una escritora que al mismo tiempo que crea a los personajes de sus novelas, se crea a sí misma como personaje que ha sido a su vez construido por los otros y que siempre se ha sentido observada y juzgada (como le sucede, en la vida real, a la mayoría de las mujeres). Así, como muchos años antes en Inglaterra, a finales del siglo XVIII, Jane Austen hiciera con su novela Northanger Abbey una revisión paródica de las novelas góticas que se habían puesto tan de moda en su época (como las de Ann Radcliffe) y cuyo público lector era particularmente de mujeres, Atwood también escribe una parodia del género — posmoderna y feminista - repitiendo sus convenciones y estrategias narrativas de manera irónica, así como sus efectos en las lectoras.

\footnotetext{
4 “La creación, el reconocimiento y el tratamiento por parte de Joan de estos 'yos' y los procesos multiplicadores correspondientes se convierte en una de las trayectorias de su historia, y mucha de su actividad consiste en ordenar a estos 'yos' por medio de la separación..."

5 "La guerra entre mi madre y yo iba en serio, el territorio en disputa era mi cuerpo [...] yo me hinchaba visiblemente, incansablemente, ante sus propios ojos, me inflaba como la masa, mi cuerpo avanzaba pulgada a pulgada hacia ella a través de la mesa del comedor, por lo menos en esto yo era invencible".
} 
De acuerdo con Linda Hutcheon, la parodia posmoderna explora y exagera las formas literarias dominantes y canónicas para desnaturalizarlas: "By both using and ironically abusing general conventions and specific forms of representation, postmodern art works to de-naturalize them..." ${ }^{\prime 6}$ (1989: 8), pero lo hace no sólo para ridiculizarlas y criticarlas sino para explorar sus posibilidades. Por otra parte, siguiendo a Brian Mc Hale, ${ }^{7}$ se trataría en este caso de una novela que se inscribe en la posmodernidad en la medida en que plantea cuestiones de orden ontológico más que epistemológico: la protagonista no sabe cómo encontrar su lugar en el mundo, ni siquiera logra explicarse el mundo como no sea a través de sus propias obras de ficción que, a la manera de otras novelas góticas, responden a patrones bien establecidos. No sabe qué hacer en el mundo, ni cuántos mundos existen; ella misma confunde la realidad con la ficción y tanto su vida como sus novelas son una suerte de palimpsesto, algo así como la reescritura de un texto encima de otro y otro.

Pero si bien la novela de Atwood es una parodia de la narrativa gótica popular y comercial, la novela que escribe Joan, la escritora protagonista (el yo que narra), no lo es. Ella escribe su novela siguiendo al pie de la letra las convenciones del género: la muchacha indefensa y huérfana, el galán — héroe y villano — poderoso y cruel, y la otra mujer que pretende destruirla; la huida, el miedo, el laberinto y el final feliz. Sin embargo, al tratar de construir su propia vida como un texto coherente que incluiría la representación de su propia muerte, fingida claro está, todo le sale mal pues nunca parece tener posibilidad alguna de controlar los hilos narrativos de su historia personal que se parece mucho, aunque ella no lo sepa, a las novelas góticas que escribe.

De acuerdo con Teresa de Lauretis, los sujetos se constituyen a partir de las representaciones y autorrepresentaciones culturales de género (y no solamente por la diferenciación sexual), el cual es una elaboración cultural tanto en su aspecto social como en su dimensión semiótica, es decir, como sistema de representaciones que otorgan sentido a la vida de los individuos en la sociedad. Siguiendo a Foucault, la autora señala que el género "como representación y autorrepresentación es también el producto de varias tecnologías sociales como el cine, y de discursos institucionales, epistemologías y prácticas críticas, así como de prácticas de la vida cotidiana" (1987:2). En Lady Oracle, Joan es víctima de dichas representaciones culturales que se convierten en autorrepresentaciones: víctima porque le son impuestas y le provocan sufrimiento al no poder asumirlas como propias. Joan "no se las cree", y en esa medida lo único que le queda es "actuar", representar el papel de mujer, imitarlo. En esto consiste su "mascarada", en esta suerte de parodia de la Mujer (con mayúscula) por parte de una mujer (con minúscula) que al mismo tiempo acepta y rechaza las convenciones sociales de la feminidad, subvirtiendo con ello la noción sobre el género como esencia y

\footnotetext{
6 "Al usar y abusar irónicamente de las convenciones generales y de las formas específicas, de representación, el arte posmoderno busca desnaturalizarlas..."

${ }^{7}$ En su libro Postmodernist Fiction (1987), McHale plantea que en la literatura anglosajona, aunque el posmodernismo surge del modernismo, ha tenido lugar un cambio de "dominante" al alejarse de los problemas de orden ontológico, centrales en la literatura modernista, y privilegiar la preocupación por el ser, de orden ontológico (9-10).
} 
poniendo al desnudo los mecanismos de la construcción narrativa de la subjetividad femenina: "The masquerade, conceived as a double strategy of acceptance and denial of femininity, is, thus, a means toward subverting all notions of a 'natural' femininity. If one can both take it and leave it, then gender becomes a performance rather than an essence"8 (Robinson, 1991: 120).

Así, Joan, la protagonista gótica, lleva a cabo una mascarada al repetir los estereotipos que la sociedad le impone, al representarlos de manera exagerada, como un exceso de feminidad, de corporalidad, de sexualidad, desdoblándose en otros personajes sin que quede claro quién es quién. $Y$ es justamente gracias a dicho exceso como descubrimos que estas representaciones culturales de la subjetividad femenina no son más que un juego paródico de apariencias. La verdad está en otra parte, o más bien en ninguna: no hay, parecería mostrar este personaje, una definición única cuando se trata de explicar a una persona, hombre o mujer, en la realidad o en la literatura.

Pero esta representación o "performance" es una especie de revancha, en primer lugar contra su madre que es la que le ha impuesto una serie de imágenes normativas de lo que "debe ser" una mujer y, en segundo lugar, frente al resto del mundo que también le impone dichas imágenes. De esta manera, la parodia gótica logra mostrar la alienación y la desintegración como insuperables y la vida cotidiana como sede del horror. Más adelante descubrimos que Joan nunca logra adaptarse a estas representaciones: ni como hija, ni como amante, ni como esposa. Es un personaje fragmentado, con una identidad escindida, con dos nombres, o más: el de soltera, el de casada, el de escritora; es una mujer que a lo largo de su vida ha actuado el papel de diferentes personajes y que siempre parece observarse a sí misma desde fuera (o por lo menos así es como lo escribe, como lo describe al narrar su historia); una mujer que nunca ha tenido control sobre su vida y que no logra construirse o inventarse una identidad, como no sea la identidad narrativa de ella como personaje de su propia novela. Al darse cuenta de su situación desesperada después de haberse metido en líos con su amante, con un crítico, con su esposo (al que le ha mentido sistemáticamente) y de sentirse amenazada por un desconocido que podría ser su propio marido, finge su muerte y huye a Italia para tratar de rehacer su vida. La representación de su muerte es también, en esta novela, una mascarada: "The idea of death as self-constructed and controlled performance, does not evoke threat, but rather ridicule, an effect enhanced by the concluding hint that the performance might have failed" (Becker, 1999: 153).

Ya refugiada en Italia y de incógnito, suponemos que ahí "escribe" el texto que leemos, texto que sin embargo quedará, de alguna manera, inconcluso. Lo último que

\footnotetext{
8 "La mascarada, concebida como una estrategia doble de aceptación y negación de la feminidad es entonces un medio para la subversión de todas las nociones de una feminidad 'natural'. Si alguien puede tanto tomarlo como dejarlo, el género se convierte entonces en una representación (performance) más que en una esencia".

9 "La idea de la muerte como un performance autoconstruido y controlado, no evoca una amenaza, sino más bien el ridículo, un efecto aumentado por la sugerencia final de que el performance pudo haber fracasado".
} 
sucede en Terremoto (el pueblo donde se esconde) es que al verse descubierta por un periodista que la había estado acechando, lo golpea en la cabeza con una botella de Cinzano y lo manda al hospital. A él le contará su historia: "I guess it will make a pretty weird story, once he's written it; and the odd thing is that I did not tell any lies. Well, not very many. Some of the names and a few other things, but nothing major"10 (378). (Nótese que quien se supone que va a escribir la historia de Joan es alguien más, un hombre, pero todavía no la ha escrito a pesar de que nosotros ya hemos llegado al final de la lectura de la narración autobiográfica, a cargo, claro, de la misma Joan.)

Joan siempre había mentido, siempre había escapado, pero ahora algo cambió, aparentemente. Esta vez no huyó ni dijo tantas mentiras y ha decidido regresar a Canadá y aclararlo todo. Sin embargo, no está segura de que le crean y piensa que al hacerse pública su reaparición todos pensarán que se trató de un truco publicitario, y que cuando el marido (a quien había estado esperando en Italia como su héroe salvador que nunca llegó) se entere de la verdad dejará de quererla, pues Joan siempre le mintió buscando eso justamente, que él la quisiera. Así, en su "vida real" no será posible el final feliz de las novelas góticas populares. Descubre entonces que en realidad nadie la conoce, excepto, tal vez, el reportero herido: “Also I've begun to feel he's the only person who knows anything about me. Maybe because I've never hit anyone else with a bottle, so they never got to see that part of me. Neither did I, come to think of it. It did make a mess; but then I don't think I'll ever be a very tidy person"11 (10).

Joan narra su vida, a la manera de un bildungsroman, a partir de un presente, un "ahora", que sin embargo sólo aparece al final de la novela ("After that, well, I don't have any definite plans"12) (379) y lo hace como una sobreviviente de los horrores a los que ha tenido que enfrentarse como toda heroína gótica. Sin embargo, aunque parece haber quedado fuera de peligro, el final de la novela no parece "cerrar" la historia y la situación de la heroína sigue pareciéndonos complicada. El final queda entonces abierto, nada se ha resuelto realmente, y estas últimas palabras de la narradora nos dejan incluso una cierta duda en cuanto a si la historia que hemos leído ha sido realmente narrada por ella misma, si es la versión que le contó al reportero canadiense o si se trata más bien de la transcripción de éste, es decir, una historia escrita por un reportero y no por una escritora (aunque claro, sabemos que la escribió Atwood)... pero sobre todo nos hace pensar que también esta "autobiografía" está plagada de mentiras o es, como toda novela, una completa y gran mentira. No obstante, y aunque Joan sigue siendo una heroína gótica hasta el final, lo es, como se dice en inglés, "with a vengeance", ya que en lugar de aparecer como víctima de las circunstancias, logra ser plenamente consciente de su situación y tomar una serie de decisiones que, aunque nadie sepa si

\footnotetext{
10 "Supongo que será una historia bastante extraña, cuando él la haya escrito, y lo raro es que no dije ninguna mentira. Bueno, no muchas. Algunos nombres y otras cuantas cosas, pero nada importante".

11 "También he empezado a sentir que él es la única persona que sabe algo de mí. Quizá porque nunca le pegué a nadie con una botella, así que no pudieron ver esa parte de mí. Ni yo tampoco, ahora que lo pienso. Sí fue un desastre; pero creo que nunca voy a ser una persona muy ordenada".

12 "Después de eso, bueno, no tengo ningún plan definitivo".
} 
tendrán buenos resultados, hacen de ella una mujer con cierta autonomía que ha podido tomar las riendas de su destino, en la medida en que esto sea posible en esta vida, o en cualquier otra.

\section{Obras citadas}

ATwOOD, Margaret. 1976. Lady Oracle. Nueva York: Fawcett Crest.

BECKER, Susanne.1999. Gothic Forms of Feminine Fictions. Manchester: Manchester University Press.

Hutcheon, Linda. 1989. The Politics of Postmodernism. Nueva York: Routledge.

Jonson, Barbara. 1989. A world of Difference. Maryland: Johns Hopkins University Press.

KaHAnE, Claire. 1986. "The Gothic Mirror”. The (M)other Tongue. Shirley NELSON, Claire KahAne y Madelon SpREngnether, eds. Nueva York: Cornell University Press.

LAURENTIS, Teresa de. 1987. Technologies of Gender. Bloomington: Indiana University Press.

Mchale, Brian. 1987. Postmodernist Fiction. Nueva York: Methuen.

MoERS, Ellen. 1985. Literary Women. Nueva York: Oxford University Press.

PIMENTEL, Luz Aurora. 1998. El relato en perspectiva. México: UNAM / Siglo XXI Editores.

RoBInson, Sally. 1991. Engendering the Subject. Gender and Self-Representation in Contemporary Women's Fiction. Albany: State University of New York Press. 